\title{
NF1 microdeletion syndrome: a phenotypical characterization of a rare case of neurofibromatosis type 1
}

\author{
Jorge Lopes $^{1 凶}$, Diogo Teixeira ${ }^{1}$, Cristina Sousa ${ }^{1}$, Armando Baptista $^{1}$, Eduarda Osório Ferreira ${ }^{1}$ \\ ${ }^{1}$ Department of Dermatology, Vila Nova de Gaia / Espinho Hospital Center, Vila Nova de Gaia, Portugal.
}

\begin{abstract}
Neurofibromatosis type 1 (NF1) is one of the most common neurocutaneous disorders, resulting from a wide spectrum of mutations in the NF1 gene. The NF1 microdeletion syndrome is characterized by a more severe clinical presentation than the majority of NF1 patients, with facial dysmorphic features, cognitive impairment, developmental delay, early-onset neurofibromas, and an increased risk of malignant tumors. This report provides the phenotypical characterization of a young boy diagnosed with this syndrome.
\end{abstract}

Keywords: genodermatoses, neurofibromatosis 1, hamartomas

Received: 3 November 2019 | Returned for modification: 13 February 2020 | Accepted: 26 February 2020

\section{Introduction}

Neurofibromatosis type $1(\mathrm{NF} 1)$ is a common neurocutaneous disorder, affecting approximately 1:2,500 to 1:3,000 individuals worldwide (1). Caused by an inactivating germline mutation in the NF1 gene on chromosome 17 , the classic manifestations include neurofibromas, café au lait macules, axillary or inguinal freckling, iris hamartomas, and optic nerve gliomas. A wide spectrum of mutations has been described so far, and some of them correlate with a specific phenotype (2).

\section{Case report}

We present the case of a Caucasian male with no relevant family history, born from a third pregnancy after two miscarriages in the first trimester. The gestation was monitored without intercurrences. The neonatal period was complicated by respiratory distress syndrome and neonatal jaundice.

From birth, the boy presented with numerous homogenous brown macules and patches between $3 \mathrm{~mm}$ and $25 \mathrm{~mm}$ across the entire body. At 3 months of age, multiple, elastic, skin-colored subcutaneous nodules began to appear. At 12 months of age a clinical diagnosis of NF1 was established, fulfilling the diagnostic criteria of six or more café au lait macules larger than $5 \mathrm{~mm}$ and two or more typical neurofibromas.

As the boy grew older, other manifestations, such as craniofacial dysmorphia, became evident. They included a coarse face, hypertelorism, a broad nasal bridge, a broad philtrum, and protruding ears (Fig. 1). The childhood development was also abnormal, with psychomotor developmental delay and a slight cognitive deficit.

A brain MRI at the age of 15 months revealed focal areas of signal intensity in deep white matter, basal ganglia, and the cerebellum. An ophthalmological examination at age seven revealed Lisch nodules in the left eye. He also developed other morphological changes, such as cryptorchidism, scoliosis (Fig. 2), and neurofibromas of the base of the tongue.
Given the particular phenotype, as well as the precocity of the cutaneous manifestations, a genetic study was requested. Array comparative genomic hybridization (Array CGH) analysis revealed a deletion of 1.29 $\mathrm{Mb}$ in the long arm of chromosome 17 (17q11.2) including several genes, among them NF1 (Table 1). This mutation is classified as pathogenic and is associated with NF1 microdeletion syndrome.

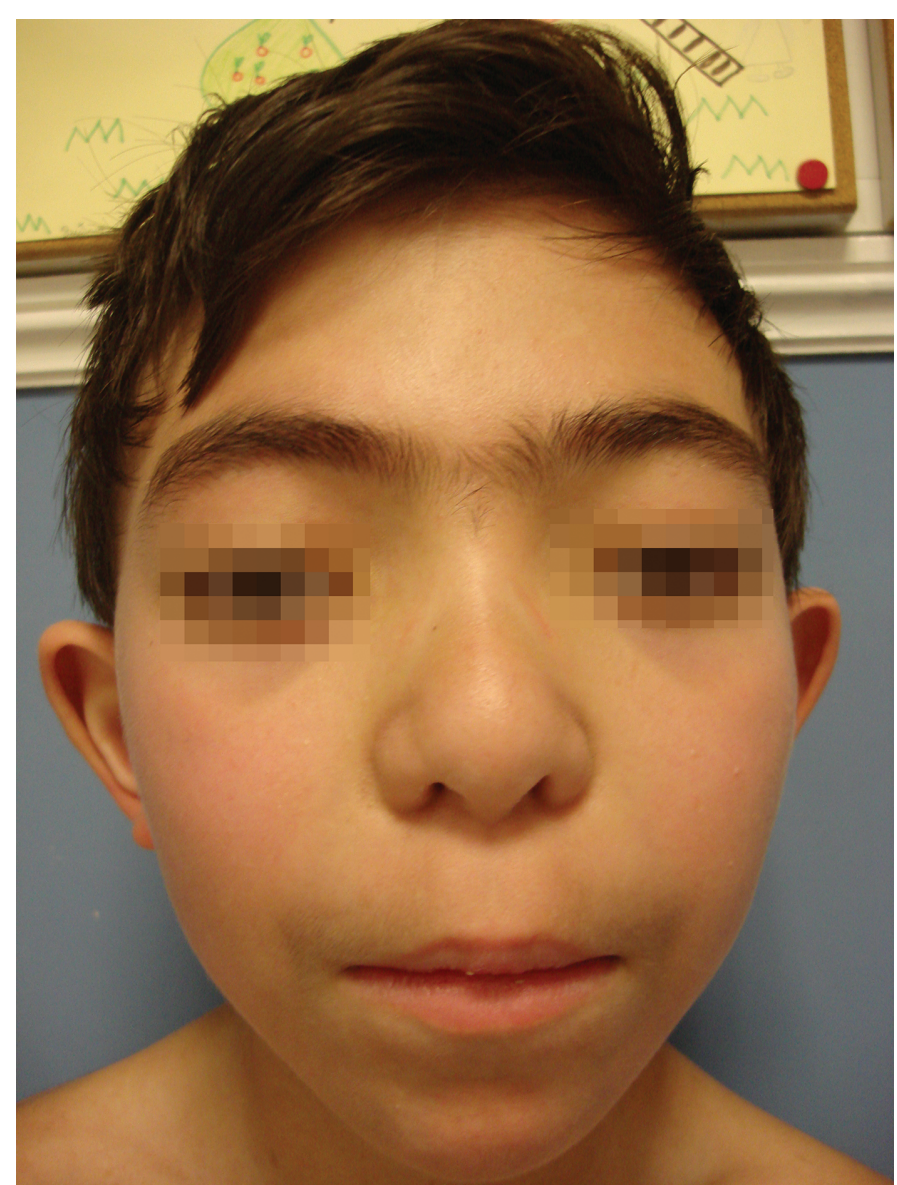

Figure 1 | The patient at age eight, showing facial dysmorphia. 


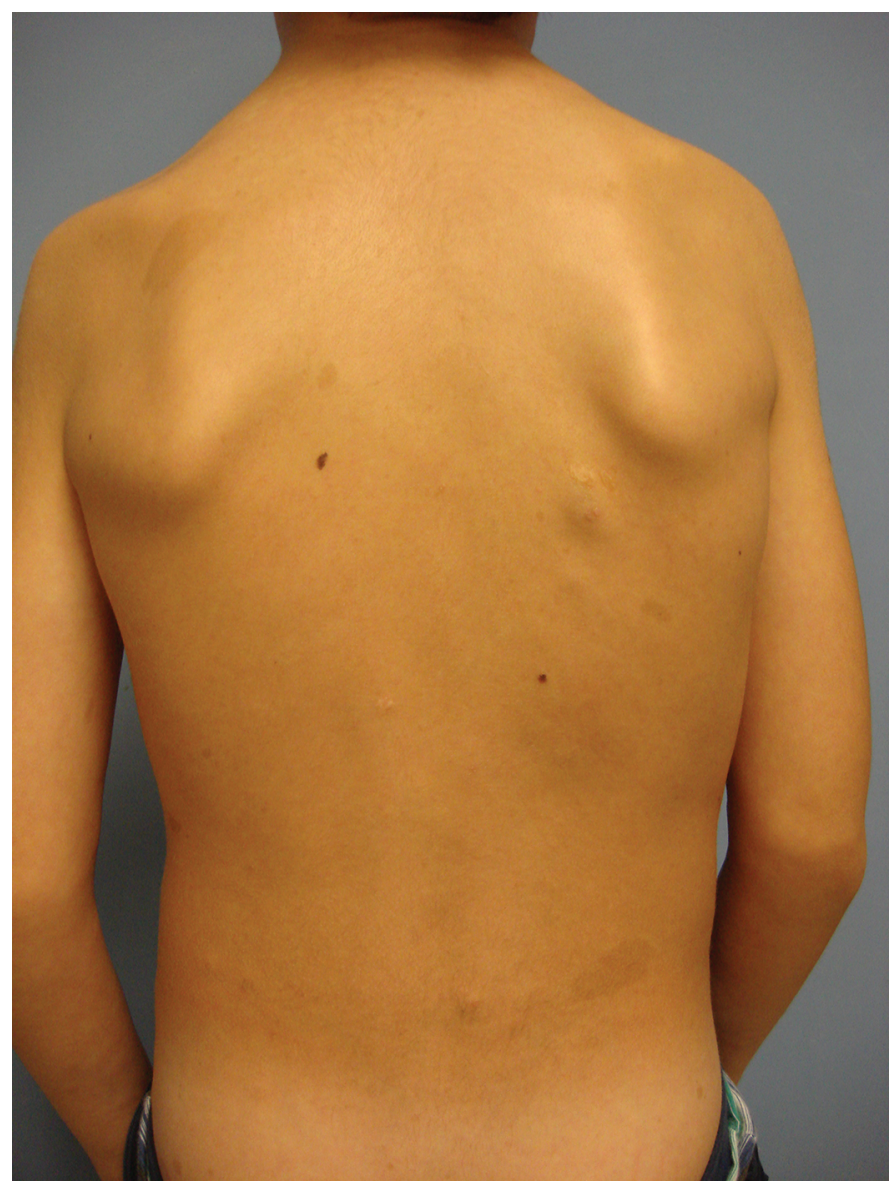

Figure 2 | The patient's back at age eight, showing café au lait macules, neurofibromas, and scoliosis.

At age eight, a massive retroperitoneal tumor was diagnosed in an abdominal ultrasound. Abdominal MRI showed an infiltrative, heterogeneous retroperitoneal mass measuring $78 \times 34 \times 59 \mathrm{~mm}$, with significant effect on the adjacent organs, encasing the aorta, inferior vena cava, celiac trunk, and superior mesenteric artery, and showing no cleavage plane with the liver. The lesion showed low metabolic activity on the PET scan. Tumor markers such as alpha-fetoprotein, beta-hCG, and urinary catecholamines were within the normal range. Despite multiple attempts at establishing a histological diagnosis, either by endoscopic ultrasound or by ultrasound-guided percutaneous biopsy, this has not yet been possible because histology has always been nonspecific.

To date, the 10-year-old boy remains under close surveillance, asymptomatic, and without a definitive diagnosis of his abdominal tumor.

\section{Discussion}

NF1 microdeletion syndrome is characterized by the presence of large deletions in 17q11.2 that encompass the entire NF1 gene and its flanking regions, and are exhibited by approximately $5 \%$ of patients with NF1 (3). The terms "large deletion" and "microdeletion" are synonymous, referring to deletions smaller than 5 megabases $(5 \mathrm{Mb})$ that include several contiguous genes but are too small to be detected by conventional cytogenetic techniques. There are three different types of chromosome 17q11.2 deletions. The deletion detected in the case at hand is the less common type 2, generated by non-allelic homologous recombination with breakpoints located within the SUZ12 gene and its pseudogene SUZ12P (4).

A literature review conducted by Mensink et al. (5) identified 157 patients with large NF1 deletions. Of these 157 patients, cognitive status was analyzed in 118 , of whom $70 \%$ showed a delay in cognitive development, ranging from mild learning disability to severe intellectual impairment (5). Recently, Descheemaeker et al. (6) confirmed that the average intelligence in individuals with NF1 microdeletions is lower than in patients without a microdeletion, although a substantial overlap exists between the two groups.

Another widely reported characteristic is an increased number of neurofibromas relative to age and their early onset (usually under age 10) (4). Plexiform neurofibromas, however, seem to have a similar prevalence to that of the general NF1 population (25-30\%) (5).

The presence of facial dysmorphia has been reported in the majority of patients with $\mathrm{NF}_{1}$ microdeletions. The most common features are hypertelorism, coarse face, broad nose, ptosis, downslanted palpebral fissures, and micrognathia. Skeletal and connective tissue anomalies were also found to be relatively common in these patients, including scoliosis, pectus excavatum, joint laxity, and mitral valve prolapse $(2,7)$.

A higher risk of malignancy has also been reported, such as malignant peripheral nerve sheath tumors (MPNSTs; lifetime risk of $16-26 \%$ ) (8). These patients should be followed closely, and complaints of pain, neurologic deficits, and rapid growth or increased firmness of tumors should raise suspicion and be thoroughly investigated. In addition, patients with NF1 microdeletions seem to have an increased risk of developing tumors not usually associated with NF1, such as cerebellar neuroblastoma, medulloblastoma, and retroperitoneal fibrosarcoma (5).

This case illustrates the classic presentation of patients with NF1 microdeletion syndrome. The early onset of neurofibromas at 3 months of age is highly uncharacteristic of NF1 without a microdeletion, leading to the study of the mutation involved. The later appearance of a large retroperitoneal tumor, which remains without a definitive diagnosis, reflects the increased incidence of tumors in this syndrome and the high level of suspicion required in the management of these patients.

\section{Conclusions}

Compared to patients with intragenic mutations, NF1 microdeletion syndrome is characterized by a more severe clinical phenotype. These individuals often have cognitive impairment, facial dysmorphism, and a large number of early-onset neurofibromas. The risk of malignant tumors such as MPNSTs and retroperitoneal fibrosarcomas is significantly higher in these patients, leading to a higher mortality rate. 


\section{References}

1. Williams VC, Lucas J, Babcock MA, Gutmann DH, Korf B, Maria BL. Neurofibromatosis type 1 revisited. Pediatrics. 2009;123:124-33.

2. Ko JM, Sohn YB, Jeong SY, Kim HJ, Messiaen LM. Mutation spectrum of NF1 and clinical characteristics in 78 Korean patients with neurofibromatosis type 1. Pediatr Neurol. 2013;48:447-53.

3. Jenne DE, Tinschert S, Reimann H, Lasinger W, Thiel G, Hameister H, et al. Molecular characterization and gene content of breakpoint boundaries in patients with neurofibromatosis type 1 with $17 q 11.2$ microdeletions. Am J Hum Genet. 2001;69:516-27.

4. Mautner VF, Kluwe L, Friedrich RE, Roehl AC, Bammert S, Hogel J, et al. Clinical characterisation of 29 neurofibromatosis type-1 patients with molecularly ascertained 1.4 Mb type-1 NF1 deletions. J Med Genet. 2010;47:623-30.
5. Mensink KA, Ketterling RP, Flynn HC, Knudson RA, Lindor NM, Heese BA, et al. Connective tissue dysplasia in five new patients with NF1 microdeletions: further expansion of phenotype and review of the literature. J Med Genet. 2006;43:e8.

6. Descheemaeker MJ, Roelandts K, De Raedt T, Brems H, Fryns JP, Legius E. Intelligence in individuals with a neurofibromatosis type 1 microdeletion. Am J Med Genet A. 2004;131:325-6.

7. Serra G, Antona V, Corsello G, Zara F, Piro E, Falsaperla R. NF1 microdeletion syndrome: case report of two new patients. Ital J Pediatr. 2019;45:138.

8. De Raedt T, Brems H, Wolkenstein P, Vidaud D, Pilotti S, Perrone F, et al. Elevated risk for MPNST in NF1 microdeletion patients. Am J Hum Genet. 2003;72:128892. 